\section{P-255 LEADING LEARNING IN A WORLD OF CHANGE: FUTURE DIRECTIONS FOR EDUCATION AND PROFESSIONAL DEVELOPMENT}

Katherine Birch, Sonja Crane. Compton Hospice, Wolverhampton, UK

10.1136/bmjspcare-2017-hospice.280

This discussion paper offers a framework for those engaged in leading and supporting learning and professional development across the hospice sector. Leading learning entails a constant endeavour to stimulate the desire to learn and sustain the engagement and co-operation of those who lead learning programmes. With an increasingly diverse staff and volunteer workforce and with many of those engaged in delivering palliative and end of life care working outwith the hospice sector, new and innovative approaches are required to look at how best to support lifelong learning across palliative and end of life care. Much has been written about new models of delivery/care within the NHS - including the emergence of Accountable Care Systems. Reflective of the challenges brought about by increasing complex care environments we would suggest that a similar approach is required for learning and professional development, whereby there is locality wide cooperation and innovation to identify and meet the learning and professional development needs of the local workforce and those within partner organisations. At the hospice, we have been leading on the development of a suite of professional development activities with other hospices, NHS providers, the Local Authority and CCG. Drawing on this experience, and reflecting on the wider literature on collaboration, partnership and innovation, this paper proposes that those involved in the strategic and operational leadership of learning need to focus on five key areas:

- a focus on learning

- creating the conditions favourable to learning

- dialogue, relationships and trust

- a shared approached to leadership through structures, procedures and programmes and

- a shared sense of accountability.

This paper explores the challenges and opportunities proposed by the framework, offering insight into potentially new approaches to learning.

\section{P-256 MARIE CURIE ECHO NETWORK - AN INNOVATIVE PRACTICE DEVELOPMENT INITIATIVE}

${ }^{1}$ Lyndsay Cassidy, ${ }^{2}$ Paula Heneghan, ${ }^{2}$ Eamon O'Kane. ${ }^{1}$ Marie Curie, Edinburgh, UK; ${ }^{2}$ Marie Curie, Belfast, UK

\subsection{6/bmjspcare-2017-hospice.281}

Introduction Palliative care is increasingly delivered in the community by health care assistants caring for people in their own homes. To ensure these lone workers are well supported and have access to evidence based education is crucial. Due to the geographical challenges, Marie Curie considered novel ways in which we could reach these workers better. Marie Curie in Northern Ireland successfully submitted a bid to be part of Project Echo NI. Project Echo is a telementoring programme which uses video-conferencing and is led in Northern Ireland by Northern Ireland Hospice.
Aim This model aimed to enable community-based health care assistants to access education, and increase their knowledge and confidence in caring for people living with a terminal illness.

Methods Project Echo uses a hub and spoke model, with members of a multi-disciplinary team being at the hub and participants logging in from around Northern Ireland (spokes). Participants generate the topics that they wish to cover in the programme of education. An educator or clinician delivers a short presentation, and then participants bring case studies which align with the topic. This ensures effective learning from the team at the hub, but also importantly peer learning. Evaluation data was collected at six time points throughout the programme.

Results Complete evaluation data will be presented. Positive evaluation results around the technology and method of learning demonstrate how this could be replicated in other areas around the country. Peer learning, sharing of experiences and access to the multi-disciplinary team were all seen as key in making the programme effective.

Conclusions Project Echo is an internationally recognised programme which has been used effectively to develop and deliver a person-centred approach to practice development. Marie Curie is now considering other areas around the UK where projects like this could be replicated.

\section{P-257 EDUCATING THE NEXT GENERATION OF HOSPICE PROFESSIONALS}

Wendy Green, Angie Pymm, Jackie Somerville, Kate Phillips. The North London Hospice, London, UK

\subsection{6/bmjspcare-2017-hospice.282}

Introduction At one time, the hospice offered work experience placements to 16-17 year-olds who were interested in pursuing a career in nursing, medicine or one of the allied health professions. These placements had to be discontinued due to the high number of learners on the ward, but we continued to receive many requests for placements. To channel this interest in the hospice, we developed a summer school programme.

Aim To provide a fun, interactive introduction to hospice care for young learners with the primary aim of helping them decide if this is the right career path for them and to assist them to enhance their CV in preparation for a UCAS application. The secondary aim was to increase awareness of the hospice in the local community and to dispel commonly held myths.

Approach We designed a three-day course, to enable learners to experience palliative care from the perspective of both the professional and the patient. Sessions were planned to incorporate various teaching methods to engage and stimulate the learners.

Evaluation The feedback was extremely positive and participants stated that the experience had changed their views about the hospice 'in a positive way', that it had provided a 'valuable experience' and had confirmed their commitment to a career in healthcare. As practice educators, we found the experience of teaching young adults was not without its challenges nor was it without its rewards. 
Conclusion Summer school is a meaningful addition to our education programme and due to this success, is to be extended in the future to cover other school holidays. Summer school has also proved to be a valuable opportunity to promote the philosophy of palliative care to those of a younger generation.

\section{P-258 EXTENDING THE CURRICULUM: BRINGING END OF LIFE CARE (EOLC) INTO THE CLASSROOM FOR YEAR 11 AND 13 STUDENTS}

Katherine Birch. Compton Hospice, Wolverhampton, UK

10.1136/bmjspcare-2017-hospice.283

Background In the past, death was such a part of everyday life it was simply and frankly discussed, but such opportunities for today's young adults are more limited. Whilst encouraging people of all ages to talk more about death and dying is important, for those considering a health-related career, having a better understanding about life-limiting illnesses and end of life care is particularly important. With many of those entering the caring professions expressing feelings of anxiety and fear in relation to death and the dying patient (Dakin, 2003) and a recognition that student nurses/doctors find caring for dying patients stress-inducing (Arber, 2001; Timmins \& Kaliszer, 2002), more needs to be done to engage young adults with topics such as complex, life-limiting illnesses, death and dying (Wardhere, 2014).

Project Reflecting this, an innovative six- week programme, 'Caring for Dave', was designed by Compton Hospice for Health Futures University Technical College, West Bromwich the first UTC in the country with healthcare and health sciences as its specialism. This challenging programme followed 'Dave' from an initial concern about his health through to care after death. Each week explored a different topic - such as lifestyles and health, breaking bad news, the dying process and caring for Dave after death. Students also completed work between sessions to enhance and consolidate their learning.

The aim of the project was to:

- Provide insight into eolc and related topics for students interested in a career in the care sector

- Explore death and dying from a range of perspectives

- Consider the personal competencies/attributes necessary to care for someone who is dying

- Encourage learners to think about a career in palliative/ eolc.

Evaluations provided very positive feedback about the programme from staff and student perspectives and the hospice is currently working with UTC and other sixth forms to explore wider roll out.

\section{P-259 INTRODUCTION OF REFLECTIVE PRACTICE FOR MEDICAL STUDENTS ON THEIR PLACEMENT IN A HOSPICE}

Rebecca Avis, Sarah Parnacott. Ashgate Hospicecare, Chesterfield, UK

\subsection{6/bmjspcare-2017-hospice.284}

Background A recent study in postgraduate education found that reflection played a vital role in helping junior doctors to learn from clinical experience. All UK doctors are expected to undertake reflection and to make this an essential foundation for lifelong learning. Medical students have an attachment with the hospice for one week during their fourth year of medical training. During this time they work with our teams on the inpatient unit, the day hospice, and in the community. Following the EAPC conference (June, 2016) when Jason Boland looked at the themes of written reflection amongst medical students in Hull, we implemented the use of a reflective piece for all our students. We sought consent from the students that their reflection be anonymised and be used to educate other professionals.

Aims To introduce reflection as a beneficial practice to students for lifelong learning.

Methods The students were asked to submit a 300- word article at the end of the week to the speciality doctor, in which they reflected upon a situation encountered during their week at the hospice that they felt had impacted upon them.

Results The range of topics was diverse and included 'The impact of certifying a patient', 'Being present when a patient or relative has been given bad news', 'A patient who wished to go to Dignitas' and 'Caring for young patients'. The medical students valued the opportunity in a supportive environment to carefully review, reflect and discuss different emotive situations that they had found surprising, distressing or inspiring during their placement. This in itself was cathartic and enabled them to receive appropriate emotional support and signposting if required to other support services before finishing the attachment.

Conclusion Reflection is a valuable tool in experiential learning, we hope this experience will endorse the value of reflective practice in their future careers.

\section{P-260 A 'CAN DO ATTITUDE' ENABLES LEARNING DISABILITIES STUDENTS TO EXPERIENCE WORK}

${ }^{1}$ Tricia Wilcocks, ${ }^{2}$ Fay Elliot. ${ }^{1}$ Ellenor Gravesend, UK; ${ }^{2}$ Ifield 19+ College, Gravesend, UK

10.1136/bmjspcare-2017-hospice.285

Background Students with Learning Disabilities (LD) are encouraged to continue in education or training to the age of 25 (Department for Education, 2016). Moving from education into work requires a supportive and structured approach. An innovative programme was established by the $19+$ college to secure supported work placements for this cohort of students. When approached the hospice was initially cautious, however, we were encouraged by the level of support on offer.

Aim To support adults with learning disabilities towards independent employment.

Method Job Coaches from the college accompanied each student with LD, ensuring they understood instructions and carried out tasks to a good standard. Placements were sought where routine tasks could be allocated for the student to learn and master and were monitored by the college. Each placement was offered initially for one academic year. Job Coaches were to pull back and observe from a distance encouraging and supporting the student to undertake tasks independently when ready. When agreed, the student would begin to attend on their own for part or a full day, working towards independence.

Results Two students attended placements all year; one in retail and he has been working towards independence; another one in the gardening and catering teams and he has been 